\title{
O PONTO ZERO DA REVOLUÇÃO: TRABALHO DOMÉSTICO, REPRODUÇÃO E LUTA FEMINISTA
}

\author{
Karla Fabiana Gomes da Silva ${ }^{1}$
}

\section{CREDENCIAIS DA AUTORA}

Silvia Federici, nascida na cidade italiana de Parma, no ano de 1942. Atualmente, professora emérita da Universidade de Hofstra, em Nova York. Filósofa, escritora e intelectual militante de tradição marxista autônoma. Atuou em 1980 como professora na Universidade de Port Harcourt, na Nigéria, onde acompanhou a organização feminista Women In Nigeria (Mulheres na Nigeria). Cofundadora do International Feminist Colletive (Coletivo Internacional Feminista) nos Estados Unidos, participou do International Wages for Housework Campaign (Campanha internacional salários para o trabalho doméstico) e contribuiu com o Midnight Notes Collective. Autora dos livros Calibã e a bruxa: mulheres, corpo e acumulação primitiva (Elefante, 2017) e detém de inúmeros artigos sobre feminismo, colonialismo, globalização, trabalho precário e comuns.

\section{SOBRE A OBRA}

O prefácio à edição brasileira da obra é dedicado a Marielle Franco, com ênfase no cenário brasileiro em que fora publicada, ou seja, a ameaça da expansão brutal do capitalismo nas relações propostas por Bolsonaro. Explica que o ponto zero da revolução é tanto um local de perda completa quanto um local de possibilidades. O conteúdo do livro é composto de um conjunto de ensaios escritos pela autora entre 1975 a 2009 acerca

\footnotetext{
${ }^{1}$ Advogada e Mestranda em Política Social pelo Programa de Pós-graduação em Política Social pela Universidade Federal de Mato Grosso. E-mail: karlafabianagds@gmail.com
} 
da questão da reprodução, dividido em três partes, quais sejam, Teorizando e Politizando o Trabalho Doméstico; Reproduzindo os Comuns; e, Globalização e Reprodução Social. Ademais, diferentemente das edições de outros países, contém um artigo denominado "Rumo a Pequim: como a ONU colonizou o movimento feminista" (2000). Os dois primeiros pontos possuem cinco capítulos, enquanto que o último ponto, quatro capítulos: Salários Contra o Trabalho Doméstico (1975); Por que Sexualidade é Trabalho (1975); Contraplanejamentos da Cozinha (1975); A Reestruturação do Trabalho Doméstico e da Reprodução nos Estados Unidos nos Anos 1970 (1980); Colocando o Feminismo de Volta nos Trilhos (1984); Rumo a Pequim: Como a ONU Colonizou o Movimento Feminista (2000); Sobre o Cuidado dos Idosos e os Limites do Marxismo (2009); Mulheres, Lutas por Terra e Globalização: Uma Perspectiva Internacional (2004); Feminismo e a Política do Comum em uma Era de Acumulação Primitiva (2010); Sobre o Trabalho Afetivo (2011); Reprodução e Luta Feminista na Nova Divisão Internacional do Trabalho (1999); Guerra, Globalização e Reprodução (2000); Mulheres, Globalização e o Movimento Internacional das Mulheres (2001); e, Reprodução da Força de Trabalho na Economia Global e a Revolução Feminista Inacabada (2009).

O livro tem sua origem pautada na experiência prática já na infância da autora, o que pode ser observado quando descreve a relação de seus genitores, em que a sua mãe era dona de casa e o seu pai trabalhava fora. Tal circunstância despertou em Silvia Federici o interesse pelo estudo sobre o tema, vindo a fazer parte do Wages for Housework Campaign (Campanha por um salário para o trabalho doméstico) no ano de 1972. A autora se utiliza do debate a posições de políticos e escritores dos quais discorda, amparada nas palavras de mulheres que a inspirou (Maria Rosa Dalla Costa, Leopoldina Fortunati e Selma James). Contudo, não esconde a sua indignação ao longo do texto sobre a marginalização da busca pelo salário para o trabalho doméstico nas pautas do referido evento e de outras feministas.

Na primeira parte do livro, partindo de um cenário vivenciado por donas de casa nas décadas de 1960 a 1970, é possível notar a defesa da autora por salário para o trabalho doméstico, custeado pelo Estado, como uma forma de estratégia revolucionária para que essa tarefa saísse da invisibilidade e do estigma de ser realizada apenas por mulheres, de modo a possibilitar que elas recusem a fazê-la no futuro, permitindo, assim, mais tempo 


\section{유드태 \\ REVISTA BRASILEIRA DE ESTUDOS DA HOMOCULTURA}

para encontro com as amigas e a luta pela mudança na sociedade em que estão inseridas.

Enfatiza após uma comparação entre as mulheres da Itália e dos Estados Unidos, que "conseguir um segundo emprego nunca nos libertou do primeiro" (FEDERICI, 2019, p. 68), justamente pela glorificação do trabalho doméstico como uma atividade altruísta, por amor. Essa situação retrata a prejudicialidade do capitalismo tanto para a mulher, quanto para o homem proletariado, uma vez que este é manipulado a ter um emprego e uma mulher para cuidar dele e ser sua dependente. E por esse motivo se vê obrigado a aceitar todas as condições impostas pelo empregador, admitindo o trabalho como única saída para a sua vida. Nessa oportunidade, extrai-se uma crítica ferrenha contra uma esquerda específica, a qual segundo Federici (2019), está focada em manter as fábricas, sem perceber que o trabalho doméstico também faz parte do capital, na medida em que produz a força de trabalho. E vai mais além ao dizer que na época de Karl Marx, este detinha o seu olhar somente nas mulheres e homens nas fábricas, e para as mulheres burguesas.

A segunda parte aborda os efeitos da globalização na reprodução social, resultante de uma imersão de Silvia Federici na África, um grande exemplo de país que teve a sua economia e população devastadas pela atuação dos programas de ajuste estrutural engendrado pelo FMI (Fundo Monetário Internacional) e OMC (Organização Mundial do Comércio). De lá para cá não houve muita conquista, o que se vê ainda hoje são as permissões de ajuda de doadores, por ela denominado "colonialismo filantrópico' "humanitário", cujo objetivo só diz respeito à dissimulação para assegurar a intervenção militar no local, melhor dizendo, "um novo rosto do colonialismo", onde pessoas são reduzidas ao nada diariamente. Nesse ponto, a autora retoma seu olhar para as mulheres, tidas como as principais agricultoras de subsistência do mundo, e que devido a isso são as mais prejudicadas, por serem deslocadas de suas terras para dar espaço à modernização da agricultura e sofrerem com os cortes nos atendimentos públicos de saúde, resultando numa intensificação na divisão do trabalho e da exploração das mulheres. Recobra a fala sobre o feminismo, crucial para as mudanças ocorridas na década de 1970, não só resultantes do ingresso das mulheres nas fábricas, mas também graças às ativistas que se recusaram ao trabalho doméstico. A globalização aumentou o proletariado com a imigração, pondo fim ao Estado do Bem-Estar Social. 
$\mathrm{Na}$ terceira parte merece destaque a explanação sobre a relação da ONU (Organização da Nações Unidas) e os movimentos feministas, que, no entendimento da autora, malgrado essa organização, tenha contribuído para garantir alguns direitos, dentre eles a Declaração Sobre a Eliminação da Violência Contra a Mulher. O movimento feminista teve seu potencial revolucionário limitado em razão das adaptações aos objetivos do capital internacional e instituições que fazem parte da ONU, ou seja, Banco Mundial, FMI e OMC - ajustes estruturais (1976 e 1985), caindo por terra as possibilidades de melhoria na vida para a maioria das mulheres acessarem serviços de educação, atendimento médico e alimentar. Outrossim, alguns temas de maior importância para as feministas não ganharam notoriedade nas conferências internacionais.

Nesse contexto, constata-se uma passagem bastante interessante na qual a autora afirma que a plataforma de ação de Pequim, inobstante a promessa de igualdade entre homens e mulheres, na verdade só prepara um caminho para a plena exploração dessas últimas, sendo, portanto, definida por Federici como "mistura de ilusões, evasões e discurso duplo" (2019, p.248), notadamente por criar feministas que atuam na órbita estatal. Diante dessa análise, a autora conclui que a intervenção da ONU representou um ajuda para enterrar o movimento feminista, asseverando que todo o desenvolvimento conquistado também seria atingido sem o auxílio da instituição.

\section{APRECIAÇÃO CRÍTICA DA RESENHISTA}

Somente ao final da leitura da obra é possível perceber a intenção da autora em publicar um livro com vários ensaios, os quais dialogam entre si numa dependência ímpar, com um tema central da reprodução da força do trabalho realizada pela mulher dona de casa. Dentre os inúmeros traços positivos da obra, está a sua importância para a discussão de uma problemática tão atual que é o trabalho doméstico, colocado sobre os ombros das mulheres desde os primórdios, redutor de potenciais criadores devido às inúmeras horas de dedicação que poderiam ser utilizadas em outros ramos no pálio da luta pela sonhada diminuição das diferenças de gênero.

Ocorre que, embora a proposta de enfrentamento mereça uma notável relevância, por ser apresentada como uma estratégia de libertação e sem desconsiderar que fora 
concebida numa época bem diferente em que ainda se arvoravam os direitos das mulheres, a medida não se mostra palpável naquele tempo e tampouco agora, primeiro porque notase uma falta aprofundamento quanto ao fundo do Estado que seria utilizado para a manutenção desse quadro de salários. Segundo, pela clara posição de discordância quanto à supervisão deste trabalho, pois como é sabido, o pagamento pressupõe contraprestação, sem a qual esse serviço guardaria uma natureza de benefício assistencial e não de emprego. Além disso, apesar de bem demonstrada a relevância do papel das donas de casa na redução dos serviços, que deveriam ser prestados unicamente pelo Estado e a sua premente contribuição no desempenho do homem trabalhador no mundo capitalista, a autora não leva em conta que o salário para o trabalho doméstico poderia representar um aumento do encarceramento da mulher, mormente pela cobrança em dobro no seu desempenho com a finalidade de que sua tarefa de servidão seja mantida, sem falar da possibilidade de ser encaradas como privilegiadas pelos demais trabalhadores.

Não isso bastasse, a sua afirmação de que são as reprodutoras da força de trabalho não se sustenta por muito tempo, sobretudo porque o lucro não é retirado do salário do empregado, mas sim do preço final do produto (MACHADO, 2020). Melhor dizendo, o trabalho doméstico (reprodutivo) não pode ser considerado produtivo, justamente pelo fato de que a sua realização se dá fora do mercado, não é socializado, destinado a troca, e, portanto, não produz mercadoria e sequer colabora com a sua circulação (ARRUZZA, 2010).

Por fim, numa crítica a Karl Marx, que ao julgo de Silvia Federici, só se preocupou com a mecanização do trabalho fabril sem se atentar com os arredores, pecando na falta de reconhecimento do trabalho doméstico. A autora deixa de levar em conta o salário do trabalhador empregado na residência para a aquisição do sustento, vestuário e moradia da família e que a luta das feministas para comporem as fábricas também carregam em si uma resistência, máxime porque a despeito da dupla jornada, a mulher que percebe seu próprio ganho guarda em si a possibilidade de com o tempo atingir a socialização do trabalho doméstico com o seu marido, pois a mudança é paradoxal, já que não adianta remunerar se não houver alteração no pensamento patriarcal. 
ARRUZZA, Cinzia. Feminismo e marxismo: entre casamentos e divórcios. Lisboa: Combate, 2010.

FEDERICI, Silvia. O Ponto Zero da Revolução: trabalho doméstico, reprodução e luta feminista. Tradução Coletivo Sycorax. 1. ed. São Paulo: Elefante, 2019.

MACHADO, Gustavo Lopes. O trabalho reprodutivo de Silvia Federici: evolução ou ruptura com o marxismo? Teoria e Revolução. Categorias Opressão e Polêmica. 2020. Disponível em: https://teoriaerevolucao.pstu.org.br/o-trabalho-reprodutivo-de-silviafederici-evolucao-ou-ruptura-com-o-marxismo/. Acesso em: 26 de setembro de 2020.

Recebido em: 30/12/2020

Aprovado em: 30/01/2021 